\title{
Psychic closure: A prerequisite for the recognition of the sign-function?
}

GERTRUDIS VAN DE VIJVER

\section{Introduction}

When Peirce stated that 'a sign ... is something which stands for something to somebody in some respect or capacity' (Peirce 1897, in Buchler 1955: 125), he clearly stressed its relational or triadic nature: if there are 'signs of meaning in the universe' (cf. Hoffmeyer 1996), they are always signs to someone, never signs as such. If signs stand for something, they inevitably stand for something to somebody. In other words, the sign-function has to be, implicitly or explicitly, recognized by someone; systems have in some sense to 'realize' the sign-function. The Peircean sign-conception is committed to a universe populated by dynamical, 'subjective', systems, i.e., beings that have developed some kind of autonomy out of which they are able to take something as standing for something else.

So, if we want to understand signifying practices in Peircean terms, it is capital to understand (i) what makes systems into systems, (ii) how their being systems leads to the capacity of realizing and/or recognizing the sign-function, (iii) whether, and to what extent, our often intuitive, human-centered understanding of the sign determines our understanding of the workings of the sign-function in other types of systems.

Biosemiotics, defined as 'the study of informational, communicative and semiotic aspects of living entities and processes' (as stated by Emmeche and Hoffmeyer in the call for papers in the present issue), argues that the above questions can, and have to be, pertinently and coherently addressed for living systems in general. It incites us to transgress the borders of human sign-practices and of human-centered ways of understanding, by considering them as part of signifying practices of living systems at large. However, it doesn't relieve us from the task of understanding in what way human systems, as living systems, express, specify, and particularize the kind of 'sign-logic' that is supposed to be at work in living systems. Nor does it relieve us from addressing the question 
of how the very specific human descriptional capacities came about and how they come to frame any possible conception of the living.

In this article, I want to start from these questions, by asking in what sense psychic, i.e., language-determined systems can be considered as a particular type of living, signifying system. I aim at understanding what it is for psychic systems, qua living systems, to realize the sign-function, and what it is for them to genuinely recognize that something stands for something else. Are there various ways of psychically realizing and/or recognizing the sign-function? What are the developmental and systemic or structural conditions leading to those capacities? Moreover, I want to understand the relationship between realizing and recognizing the signfunction for psychic systems. Is the recognizing a precondition for the realizing or is it the other way around?

Psychodynamic structuralism (Freud 1950c, 1915e; Lacan 1966; Petitot $1985,1990)$ as well as developmental and evolutionary systems theory (Depew and Weber 1995; Griffiths 1994; Kauffman 1993; Salthe 1985, 1993; Van de Vijver et al. 1998) serve as my main background, but the approach presented here is on many points convergent with the aims and ambitions of the biosemiotic program. Indeed, if we agree (i) to consider organizational closure as a minimal condition to be fulfilled for dynamical systems to be stable, self-maintaining and self-producing, ${ }^{1}$ (ii) to conceive of living systems in terms of intricate organizational closures that set the stage for meaningful interactions (cf. Kauffman 1993; Maturana 1988; Maturana and Varela 1980, 1987; Pattee 1995; Rosen 1985, 1991; Varela 1979), and (iii) to situate the psychological realm in continuity with this viewpoint, then our task will be, minimally, to understand the status, the meaning, and the implications of closure at the psychological level. What can be meant by psychic closure? What makes psychic systems into systems? What mechanisms are at work that lead initially biological systems to close themselves organizationally and to become psychic systems of a certain kind? How do psychic systems acquire the possibilities of entering into meaningful interactions?

I shall begin by putting into parallel the biosemiotic and the psychodynamic point of view, illustrating the relevancy of interchanging very specific questions between domains as apparently divergent as biology and psychology, as well as highlighting the theoretical continuity with regard to closure. The presentation is quite abstract and schematic, and aims in the first place at suggesting and exploring new paths of research. I will argue that the psychodynamic structuralist viewpoint, in which mental phenomena are conceived of in materialistic, structuralist, and dynamic terms, is in line with the biosemiotic approach to the living. Next, I will discuss the meaning and the role of the mechanism of 
identification in the constitution of psychic closure. In my viewpoint, the mechanism of identification is crucial in establishing any kind of psychic closure; it is what makes psychic systems into systems of a certain kind, because it involves the formation of a self-referential, i.e., closing judgment. The different ways in which identification has worked in particular histories leads to different types of psychic closure, and eventually to different kinds of psychic structure. In their turn, psychic structures are determinative for the signifying practices of the psychic system, qua living system; they determine the scope and the nature of the interactions considered as meaningful. In conclusion, I will ask whether identification can have a meaning beyond the psychical realm, and formulate some future paths of research along these lines.

\section{Biosemiotics and psychodynamic structuralism}

One of the main theses of biosemiotics, is that there is an intricate relationship between what makes living beings living, and what makes them into systems capable of acting and behaving in meaningful ways (cf. Hoffmeyer 1996; Van de Vijver 1997). If living systems are able to entertain meaningful interactions with an environment, it is because they are living systems. In other words, if living systems are able to interpret their surroundings, it is, minimally, because they are organizationally closed systems. Closure provides them with a form of stability, protecting them from being invaded or destroyed by stimuli of all kinds, and leaves openness for new, potentially meaningful stimuli that arise from contacts with the world. Moreover, closure provides the context from which to interpret the surroundings. ${ }^{2}$

Evidently, the intricate linkages between openness and closure, their multiple manifestations, their ingredients at various levels, and their evolution and development need to be made precise at various levels of the living. It is clear, also, that a central task for a biosemiotician will be to account for the detailed systemic conditions within which meaningful interactions can take place. Additionally, he will have to account for the emergence of those systemic conditions. In other words, he will have to explain the material conditions within which certain stable structures come about and how they come to fulfill a constraining role for future behavior and future development. ${ }^{3}$ And, last but not least, he will have to address these questions with regard to living systems in general - i.e., indifferently of whether, for instance, animals or humans are concerned - while situating them within the confines of the typically human descriptional capacities. 
The advantages of the biosemiotic approach are manifold.

Firstly, it avoids addressing the question of 'what separates man from the other animals' (cf. Diamond 1997) in largely implicit anthropomorphic terms. By analyzing the sources of the signifying practices in living systems at large, these are no longer suddenly and mysteriously belonging to 'higher' animals only.

Secondly, it avoids playing functionalist and semiotic arguments against each other. In neo-Darwinian biological evolutionary theory, the following move is quite common: from the moment the functional evolutionary account can no longer be taken as plausible - some trait is no longer useful in the light of reproductive success; it has become a 'functionally unnecessary luxury' - attention is turned to semiotic arguments - i.e., arguments that refer to the signal- or sign-value of things. In the biosemiotic approach, on the contrary, the biologically functional and the semiotic are inseparable from the very beginning. ${ }^{4}$

Thirdly, in biosemiotics there is a quite logical connection between the 'signal-value' and the (evolutionary) intentional organization of the living (cf. Hoffmeyer 1996: 47). Instead of relegating the 'opportunity to design' (cf. previous note) to specific types of living systems, and instead of considering that only a few systems are capable of acting according to 'what they would want to be like', biosemiotics proposes an active, constructive view of the living since its beginnings. The possibility of constructing and/or embodying aims, whether consciously or not, is intimately connected with the fact that living systems are anticipatory from the very beginning. As a consequence, instead of sticking to an externalist viewpoint - assessing the usefulness of certain traits on the basis of functionalist criteria external to the system under observation an internalist viewpoint is likely to be much more appropriate in this regard. ${ }^{5}$

Fourthly, the connection between the biologically and the semiotically functional rests on the possibility of constructing socially meaningful relations: there has to be, from the very start, an audience for a signal. If the living is semiotic, sociality - however minimal - is present with the living since its beginnings. ${ }^{6}$

Finally, by arguing for the hierarchical organization of the living - i.e., the hierarchical organization of closures through evolution and development - biosemiotics cannot consider language, or culture, or any other factor playing a developmental role at a certain level, as a kind of veneer. The challenge here is to account for the developmental constraints that had a determinative impact in the construction of the system. Those constraints cannot be considered as veneer in comparison with those at work in underlying levels of organization. At each level appropriate paths of 
determination are formed, and each level functions accordingly. Nature has, at various levels, ways of taking habits. ${ }^{7}$

The general message of biosemiotics thus goes as follows: first, understand the developmental and evolutionary constraints at work at the various levels in living systems, then define the types of determinations that ensue, and finally, explain the concrete signifying practices on this basis. In this way, it could be said that biosemiotics subscribes to a generalized de-black-boxing of the living. Living beings cannot be faithfully dealt with on purely external grounds, they cannot be adequately assessed when conceived of as entities 'frozen in the record' (Matsuno and Salthe 1995). Living beings essentially develop and essentially subsist in an interactionist, social context; they are from the very start signifying beings; they are essentially defined on the basis of sign-practices in a social context.

How can the psychodynamic structuralist approach be considered as a specific instance of the biosemiotic program? In what sense are the questions it addresses basically similar to the biosemiotic questions as briefly sketched above?

In psychodynamic structuralism, psychic phenomena are conceived of in materialist, dynamic, and structural terms. The material aspect refers to the fact that psychic phenomena are of a material nature and need to be apprehended on the basis of specific, concrete mechanisms applicable to material elements (cf. Freud 1950c [1895], 1915e; Lacan 1993 [1955-1956]; Van de Vijver 1998). The dynamic aspect refers to the fact that matter can only be shaped through a particular developmental history. The structuralist aspect refers to the more or less fixed results of this particular history, the particular pathways that were formed, that continue to be formed throughout a lifetime and that determine subsequent behavior.

The previously described connection between living, systems, and signifying practices equally holds for psychic systems: if psychic systems, qua living systems, are able to interpret their surroundings, it is because they are organizationally closed systems. Closure provides them with a form of stability that protects them from being invaded or destroyed by stimuli of any kind, and leaves the essential openness for new potentially meaningful stimuli that arise from contacts with the world. Here also, closure provides the context from which to interpret the surroundings.

If organizational closure generally refers, as we have seen, to the selfreferential organization of the causal interactions between certain material elements, then the specificity of psychic closure will have to be articulated (i) starting from a specification of the relevant material elements, and (ii) on the basis of an explicitation of the specific 
mechanisms of closure at work in this context. The answers here will depend upon what one considers as basically determinative in a psychic developmental history, and are likely to differ with the variously proposed viewpoints. For instance, there can be discussion about the nature of the material elements: they can be considered as representations, as in the Freudian tradition, as 'imagos' or as signifiers, as in the Lacanian point of view. ${ }^{8}$ The point I want to focus on here, however, is their particular organization and the mechanisms at play in that regard. But before addressing that topic in more detail, let me stress the further similarities between biosemiotics and psychodynamic structuralism.

As in living systems at large, it will be capital here also to analyze the linkages between openness and closure, to describe their multiple manifestations, to analyze their ingredients at various levels, to account for their evolution and development in terms of general principles and mechanisms, and, of course, to always take into account the implications of ourselves being living systems in describing the living. In this way, the psychodynamic program instantiates the dynamics of the living, and as such it involves, as is the case with any new hierarchical level of the living, a new dynamics of interpretation. The major task of psychodynamic structuralism is to define the relevant mechanisms, to explain the typical constraints, and to describe the various modalities of psychic being.

The advantages are quite similar to those enumerated for the biosemiotic program.

Anthropomorphism is less evident because no psychic structure can be considered as representing the exquisite point of reference. The various modalities of psychic structuration display, within their interactive domain, the principles of their signifying practices. Anthropomorphism in this case would mean that an interpretation is developed within one interactive domain and is uncritically projected onto another domain, as if it represented the absolute external viewpoint for all types of psychic structures.

As in biosemiotics, the artificial cleavage between functional and semiotic arguments loses its pertinency, as the semiotic reasoning is applicable to psychic systems, qua living systems, from the very beginning.

Moreover, the 'signal-value' of things is closely related to the intentional organization of the psychic system. ${ }^{9}$ Psychodynamic structuralism proposes an active, constructive view of the mental, and opens up to the idea that psychic systems have a variety of ways, and a variety of degrees, of being alive. In other words, one can be perfectly alive from a purely organismic point of view, but barely alive mentally. There is a balance between openness and closure to be specified in each case. 
Furthermore, sociality is crucial in the construction of psychic systems, as well as in the development of socially meaningful relations. There has to be, from the very start of psychic life, an audience for a signal. This aspect has been acknowledged from different sides in psychology, but the precise role of the other in the constitution and the signifying practices of different psychic structures mostly remains to be made explicit.

Finally, it is relevant to think of the psychic system as embedded in the hierarchical organization of the living, but also as hierarchically organized itself. Language, or culture, or any other factor playing a developmental role, can therefore never be considered as a kind of veneer. The challenge here is to define the developmental constraints that had a determinative impact in the construction of the psychic system. It will be those constraints that will allow us to understand the psychic system as a living system of a particular kind. In this regard also, it is inspiring to think of

\section{Table 1. Biosemiotics for biological and psychic systems}

Biological systems

'signs stand for something to somebody in some respect or capacity' (Peirce)

\section{living systems}

- types and stratification of closure

- types and stratification of openness

sociality

emergence of the code \& emergence of the organization of the code $=$ triadic or relational (cf. Hoffmeyer 1996)

multiple ways of being

multiple ways of interpreting, signifying, remembering, forgetting, repeating and inventing (cf. Hoffmeyer 1996)

inside and outside

what falls within the scope of the interactional domain of the system is the inside

epistemological implications

role of the gap (cf. Hoffmeyer 1996)
Psychodynamically structured systems

'signs stand for something to a psychic system in some respect or capacity'

psychic structures

- types and stratification of closures

- types and stratification of openness

sociality

emergence of the psychic

structure $=$ triadic or relational

multiple ways of being

idem, cf. materiality of the signifier

(Lacan 1955-56), role of the record

(Matsuno \& Salthe 1995), repetition

(cf. Reyniers \& Van de Vijver, 1998)

inside and outside

what falls within the scope of the interactional domain of the psychic system, either symbolic and/or imaginary, is the inside

epistemological implications role of the gap in any description, redoubled here by the identificatory gap, related to grasping of one's own being in a self-referential judgment 
the psychic system as a metabolism, or to speak of the metabolism of the signifier (cf. Note 8).

Let me summarize the parallels between biosemiotics and psychodynamic structuralism, and schematically anticipate the next section, which deals with the constraints specifically at work in the constitution of psychic systems, and in particular with the mechanism of identification in psychic closure (see Table 1).

\section{The mechanism of identification: A basic mechanism for psychic closure?}

As we have seen, it is necessary to define the mechanisms at work in the construction of psychic systems, and to make explicit the ways in which psychic structures are determinative for particular signifying practices. My aim here is to understand what it is for a psychic system to realize or to recognize something as a sign in a Peircean sense, i.e., as something standing for something to somebody in some respect or capacity. The basic idea is that if psychic systems, qua living systems, are able to interpret their surroundings, it is because they are organizationally closed systems. So: what kind of mechanism is likely to be at work in psychic closure?

I have stated that closure refers to the self-referential organization of the causal interactions between the relevant material elements. The hypothesis I want to put forward now is that the mechanism of identification is the basic mechanism in realizing psychic closure, and hence, the basic mechanism at play in the development of signifying practices.

The following subtheses constitute the 'flesh' of the main hypothesis:

(i) the mechanism of identification is crucial in establishing any kind of psychic closure; it is what makes psychic systems into systems of a certain kind;

(ii) identification, by definition, concerns the formation of a selfreferential, i.e., closing judgment: it involves the internalization of a specific external element, and thus installs a new level, or a new order of being, the psychic level;

(iii) the self-referentiality involves an 'appropriation' and integration, or a reorganization of elements of a lower level. Here, identification (minimally) implies the appropriation of the biological, organismic body, allowing the distinction between the biological and the psychic to emerge;

(iv) identification can take place either imaginarily or symbolically: the former concerns the identification with the image in the mirror, it provides the unity of the body via its presentation in the image; the latter concerns the identification with the signifier 
(Lacan 1977 [1964]); taking a signifier as standing for one's own being in some respect, involves the internalization of the triadic nature of the sign itself, leading to the recognition of the signfunction interpreted in relational terms (see Note 8);

(v) only in some types of psychic systems is the distinction between internal and external explicitly, i.e., symbolically, recognized; this recognition is dependent upon the possibility of building symbolic identifications;

(vi) the different ways in which identification has worked in particular histories will lead to different types of psychic closure, eventually leading to different kinds of psychic structure;

(vii) psychic structures are determinative for the signifying practices of the psychic system, qua living system; they determine the scope of the interactions considered as meaningful.

All these points would deserve a much closer analysis, theoretically as well as practically, but it is impossible to deal with all of them in detail here. I can only briefly indicate why and how this picture is plausible, how it unifies some existing insights, again on a theoretical as well as on a practical level, and what perspectives it contains for future research.

\section{The internalization of an external element}

Identification concerns the way in which a living being succeeds in recognizing itself, in building a representation of itself, or in giving itself a place in function of the outer world, on the basis of an interaction with his surroundings (cf. Grunberger et al. 1978). As perceiving systems - the 'perceptual substance of the living organism', as Freud would call it (1915c: 119) - living beings normally do not stand in a relation of cognitive self-evidence to themselves. The element that is likely to reveal to them their own nature is the constant stimulus. By identifying with the constant stimulus, by recognizing itself in the stimulus, the organism acknowledges his own unicity. This is what René Thom and many ethologists, among them Lorenz and Eibl-Eibesfeldt, acknowledged when they stated that the moment the predator chases the prey, the predator is the prey. Along similar lines, when I say 'I', this does not just indicate my organic individuality, but on the contrary it refers to the organic individuality as strictly equivalent to the mirror in which that organic individuality is revealed. ${ }^{10}$

But the peculiarity of humans is that they are not just organisms. They do not restrict themselves to imaginary identification. Humans are born in language, and most of the time come to assume the idea that words can 
represent them, thereby immediately experiencing the inadequacy of words as they can never fully represent them. Symbolic identification concerns the identification with the signifier (Lacan 1977 [1964]), it involves taking a signifier (trait unaire) as standing for one's own being in some respect.

In both imaginary and symbolic identification, however, one always identifies with what one is not. Freud is very blunt on this point in the first pages of Instincts and their Vicissitudes (1915c). His main idea is the following: 'all that I can directly withdraw from, this is not me; on the contrary, all that I cannot directly withdraw from, this is me' (Dalto 1998: 265). What I cannot escape, that is me. To Freud - and this is of importance in view of the parallels we have been drawing between biosemiotics and psychodynamic structuralism - this means that the thing that I cannot escape, is a thing that stays together and impresses by its constant structure. This thing can be me.

So, in saying that identification involves the internalization of an external element, I don't mean to imply that the external element is arbitrarily chosen. On the contrary, it must find its basis in the acknowledgement of things that 'stay together as a thing'. Here, we encounter the intimate link between identification and sociality. It is true that one identifies with what one is not - internalization of an external element - but one nevertheless identifies with somebody or something that is perceived, however partially, as basically the same. To rephrase it in other terms: one identifies with an organizationally closed system of a certain kind. To identify, is to subscribe to the signifying practices of at least one other being at the relevant level of organization.

The particular material conditions necessary for being in this way in language, remain, however, highly mysterious. The fellow human being and his way of being in language, are certainly determinative. It could be interesting to consider the fellow human being in terms of perturbations of the biological structure of the organism. The other perturbs in a more or less drastic way the present biological rhythms; he perturbs the various productions of the child by interpreting them, he perturbs the child by being absent or present. Thus we have two interacting structures, one that is in language in a particular way, the other that is not yet in language but that is underinterpreted and at the same time overinterpreted. However, it seems to me that we are far from having stipulated the conditions for or the details of the mechanisms that are at work here.

\section{Closure over the organismic body: Embodiment?}

The general idea I present here mostly took shape while I was studying various case studies of psychosis. ${ }^{11}$ In these cases, the difficulties of 
establishing imaginary as well as symbolic identifications go hand in hand with the difficulties or peculiarities prevailing in the signifying practices. As a matter of fact, the capacity for recognizing that something is a sign i.e., the capacity for recognizing that something can stand for something else, and, by extension, that a sign can potentially stand for anything heavily relies on the ways in which one has succeeded in applying this signifying practice to one's own being. The capacity for recognizing the signfunction clearly requires the capacity for including one's own (organismic) being in a self-referential, i.e., identificatory, closing judgment. The capacity for recognizing the sign-function requires that one has unified, i.e., enclosed, his own body on the basis of a signifying judgment. A sign can only be recognized as such when someone has succeeded in making a selfreferential judgment by which he takes a sign as something that stands for $\mathrm{him} /$ herself in some respect or capacity. This is, according to me, the proper way in which embodiment should be interpreted. In opposition to many approaches in cognitive sciences, embodiment should not be seen as a kind of sophistication or contextualization added after having developed formal approaches of the mental, but has to be conceived of as a factor included from the very start in the development of the mental and the cognitive. If there are as yet no machines that possess embodied knowledge, it is minimally because they haven't yet closed themselves by selfreferentially judging their own being.

In cases where a human being has not succeeded in signifying his own being - in cases where he has not grasped himself as something that 'makes an impression by its constant structure and that stays together as a thing' (cf. Freud 1950c [1895]: 331) — it can be shown that a sign is not generally something that stands for something else to somebody in some respect or capacity. It can be observed that most psychotic beings have immense difficulties when in front of a mirror, because they are not able to recognize themselves in it and consequently experience the image as a major threat to their own being. Moreover, signs that are in any sense related to the proper body are frequently considered as things with a threatening character. ${ }^{12}$ Moreover, in those same cases, there is a marked difficulty in treating one's own body as something that is in some sense unified. There is no real sense of internal and external: time and again the organismic body needs to be carved or mutilated to reassure the person in question that he 'has' a body, an understanding that is quite far from recognizing that he 'is' someone. ${ }^{13}$

If I may expand speculatively upon the idea of embodiment, I would say that by realizing the self-referential judgment about one's own being, one exquisitely subscribes to the dialectics of closure. The symbolic identificatory judgment implies the acknowledgment that language is a means 
of externalizing, i.e., a means of closing off the internal dynamics. As a matter of fact, it implies that one has installed, within oneself, the means of establishing a judgment that remains forever external to the proper internal dynamics, by assuming that there is at least one sign that can stand for the internal dynamics. This is what I mean when I say that, by symbolic identification, the dialectics between inside and outside has been internalized (cf. iv, v). But it also involves the internalization of the triadic nature of the sign itself, because entering language implies that one accepts the fundamental impossibility of making the word and the thing coincide. As a means of externalizing, language is marked in a twofold way by a fundamental gap. Firstly, the code itself is marked by a gap: something escapes in any codification. In Signs of Meaning in the Universe, Hoffmeyer (1996) beautifully describes this in terms of semiotic freedom: precisely because it is based on exclusion, the code can create semiotic freedom. Robert Rosen, and also Jacques Lacan arrived at very similar conclusions in characterizing the modeling relation. Secondly, there is a gap that arises once we introduce the idea of system or of closure, and that redoubles the previous one. The gap here refers to the impossibility of adequately describing the internal dynamics of living systems, and the necessity, faute de mieux, to adopt an external, however partially totalizing, viewpoint to account for it. It is a gap that, in the field of evolutionary biology, leads to the difference between internalist and externalist viewpoints (or the endo-exo discussions of which the main proponents are Koichiro Matsuno, George Kampis [1991], and Harald Atmanspacher [1996]). For human beings, this issue is precisely the one of identification: how to know fellow human beings, or even fellow living beings, when considering the fact that they are systems, and that it is impossible to break them apart without destroying them as systems?

In summary, the way of being in language participates in the dialectics of the living; it quite naturally, though not unambiguously, expresses the way of being in the world, in a bodily, spatial, and temporal manner. The biological is a reappropriation in language for beings who are produced in and through language. I can paraphrase here Maxine Sheet-Johnstone's statement: 'Animals are topological beings: they move as they shape and they shape as they move' (Sheets-Johnstone 1996), as: 'Humans are topological beings: they speak as they shape and they shape as they speak'.

\section{Conclusion}

My presentation of identification as the basic mechanism in psychic closure has been very schematic, abstract, and theoretical. The coherence 
and the pertinency of the approach evidently need to be further elaborated, in the first place on the basis of clinical fragments, but also on the basis of a study of the workings of closure at other biological levels. It would indeed be interesting to see whether identification is only a 'window' for the understanding of closure at the psychic level, or whether it has any implications for living systems at large. If biosemiotics claims that there is sociality in the living from the very start, then why not conceive of that sociality in terms of identificatory mechanisms even for very primitive living beings?

Another interesting line of research would consist of studying the dialectics between internal and external at various levels. What came out so clearly in the case of psychic systems, is that a new level is only distinguished as such when it has in a sense been closed off, i.e., when one has been expulsed from it by creating the closure over its material elements. In this way, psychic beings, from the moment they have 'embodied' their being, no longer have 'privileged' access to the kind of organismic unity as we might suppose is the case in animals that didn't succeed in building identificatory judgments. Insofar as we are language-determined systems, and insofar as we are in language, we don't have privileged access to our organismic unity. In speaking, one can have acquired a new kind, a linguistic kind of body, un corps, as Lacan would have it. In more general terms, the 'higher' level is not really a meta-perspective on the lower levels. The higher level adds a new perspective, and provides us with external viewpoints that, inevitably, remain ing equate to account for the internal dynamics at play between the relevantwhaterial elements. This does not lead to a solipsism, as is sometimes advanced when dealing with organizational closure or autopoiesis (cf. Kampis 1991: 389, cf. Note 2). In our argumentation, identification is a window on a world, but it is also a creation of a world in which one is not solipsistically enclosed, but one in which the conditions for understanding need to be, time and again, created through interaction in a social context.

\section{Notes}

1. I use the concept of closure in a quite relaxed sense throughout the article: it refers to the self-referential organization of material elements of a certain kind. More details and a critical notice can be found in Note 2 .

2. Closure has many meanings. Here, it abstractly refers to the self-referential organization of the causal interactions in material systems, i.e., to the self-referential, recursive organization of the causal loops that determine the particular dynamics at a certain level (cf. Maturana and Varela 1980; Varela 1979). Organizational closure clearly does not imply that the system under consideration is closed to energetic or material interactions. 
In this sense, my interpretation is faithful to Maturana's and Varela's interpretation of closure, as it is embedded in their theory of autopoietic systems (Maturana and Varela 1980; Varela 1979). According to these authors, an autopoietic system is 'organized (defined as a unity) as a network of processes of production (transformation and destruction) of components that produces the components that: (1) through their interactions and transformations continuously regenerate and realize the network of processes (relations) that produced them; and (2) constitute it ... as a concrete unity in the space in which they exist by specifying the topological domain of its realization as such a network' (Varela 1979: 13). In this definition, the capacities of self-production and self-maintenance of systems are stressed, and explicitly related to the specific organization of the relations between their components. It is these capacities and the organizational requirements underlying them that I am interested in here. The epistemological difficulties traditionally linked to autopoietic systems theory, i.e., those about their so-called solipsistic nature, or those about the nature of signs or representations, considered as 'phenomena existing only in the domain generated by the observer' (Maturana and Varela 1980: 132), are still subject for discussion. They merit study in detail, at each relevant level, because the assumptions they involve are multiple and make it impossible to bluntly state the problem in terms of logical incompatibilities. Unfortunately, such an endeavor falls outside the scope of this article.

3. This is what makes the biosemiotic program so closely related to the dynamic structuralist and basically materialist program of evolutionary systems thinking (cf. Van de Vijver et al. 1998).

4. A small example might be helpful to illustrate the respective 'ranges' of the functionalist and semiotic arguments in biological evolutionary theory. In 'What separates man from the animals? Four inches and eleven minutes' (Diamond 1997), Jared Diamond deals with the differences between human and animal sexuality, as well as with 'the evolution of body signals of exaggerated size and confined to one sex, which serve as social signals'. The article plays very much on the comical side of the affair, exploiting, among other things, the difference in length theen the human and the simian penis, and the plausible explanations accounting for this difference. In this regard, the author writes the following: 'The erect penis is about one-inch long in gorillas, one inch in orangutans, but five inches in humans, even though male apes have much bigger bodies. Are those extra inches a functionally unnecessary luxury?' And he goes on to answer: 'A hint that the large human penis serves as some sort of signal is offered when men have the opportunity to design their own penises, rather than remaining content with their evolutionary legacy. Men in the highlands of New Guinea do that by enclosing the penis in a decorative sheath called a phallocarp. The sheath is up to two-foot long and four inches in diameter ... . Each man owns several, varying in size, ornamentation and angle of erection, and selects a different one each day, much as we select a shirt to wear. Asked why they wore phallocarps, the tribesmen replied that they felt naked and immodest without them. ... The phallocarp is in effect a conspicuous erect pseudo-penis representing what a man would like to be endowed with' (italics added). We observe here, as opposed to the biosemiotic viewpoint, that Diamond assumes a distinction between the 'merely' functionally explainable and the semiotically explainable, and that he links the latter with the possibility of design according to 'what one would like to be'.

5. For a more detailed account of the distinction between internalism and externalism, see, for example, Matsuno (1996) and Van de Vijver (1996).

6. Quite to the contrary, Diamond holds that it is only with semiosis that we enter that other kind of functionality, i.e., the social, interactive kind in which biologically useless things can become, surprisingly, extremely useful. As a matter of fact, the article ends 
with a question about the 'intended audience' of the above 'proclamation of virility', thereby opening up the issue of sociality. An easy answer is not to be expected, Diamond says, but the tentative one we get here is the following, again based on an implicit anthropomorphic move: 'Zoologists studying animals regularly discover that sexual ornaments serve a dual function: to attract potential mates of the opposite sex and establish dominance over rivals of the same sex'.

7. Again in opprosition to this viewpoint, Diamond's article ends with: 'we humans still carry the legacy of hundreds of millions of years of vertebrate evolution engraved deeply into our sexuality. Over that legacy, our art, language and culture have only recently added a veneer'.

8. According to Lacan, the imago is constitutive for the formation of the psychic system in that it provides the image with which one identifies. For the role of the imagos in the constitution of a psychic system, see 'Propos sur la causalite psychique' (Lacan 1946, reprinted 1966). Surprisingly, in this text Lacan already speaks of closure when dealing with the identification with the image, and in particular when focusing on the Oedipus complex. He writes: 'Its value of closure [of the Oedipus complex] in a psychic cycle has to do with the fact that it represents the family situation, which, by its institutional character, marks, in the cultural realm, the crossing of the biological and the social' (Lacan 1966: 184, my translation). (In French: 'sa valeur de clôture d'un cycle psychique tient à ce qu'il représente la situation familiale, en tant que par son institution celle-ci marque dans le culturel le recoupement du biologique et du social'.) This quote is particularly relevant in the light of the biosemiotic interpretation of the living in basically social terms.

In addition to the imago, Lacan stresses the importance of the signifier. A signifier is by him interpreted along the lines of Saussure's structuralism, with the basic difference that he doesn't focus on the structure of language, but on the psychic structuration on the basis of language. Here again, as we will see further, in this process of psychic structuration, identification will play a crucial role. As a matter of fact, in symbolic identification, or the identification with the signifier, the subject takes a signifier as representative for his being, however partial that may be. I would say that the signifier is an expression of the way in which the subject has 'categorized' his (mainly linguistic) surroundings in a structuralist way. Signifiers can be words, or other kinds of linguistic material (morphemes and phonemes), and as such they are particular organizations of the linguistic material that have had a structuring impact on the subject. But they don't need to be linguistic, as objects, relationships, and symptomatic acts can be signifiers as well. Crucial for a signifier is its material nature, which refers to its indivisibility. This makes it into the building block of psychic organization, which is conceived of accordingly in material terms. Whereas Lacan conceived of the signifier as something that is inscribed in a system and which takes on a psychic value purely by virtue of its difference from the other elements (Saussure's interpretation of structure), I believe it is interesting to attempt conceiving of psychic structure along the biosemiotic lines we have been sketching, that is, as a living, organizationally closed system. That is why it is interesting to conceive of the psychic system as a 'metabolism of the signifier', a metaphor that was used by Jean Guir (1998). In this endeavor, it is crucial to arrive at a clear definition of psychic organization or structure, which is what the present article sets out to do. For the role of the signifier in the work of Lacan, various works can be mentioned. Apart from the text above, see Lacan (1961-1962); Evans (1996).

9. This holds for the conscious 'part' or functioning of the psychic system, as well as for the unconscious. In this regard, interesting analogies have been brought to light between Freud's and Brentano's approaches to intentionality. (Cf. Cohen 1998.)

10. I was much inspired here by the article by Sylvana Dalto (1998). 
11. Many cases could be mentioned here, but one has been particularly revealing to me, namely, that of little Herbert, described by Edita Sterba at the beginning of the century (cf. Sterba 1933a and b).

12. Beautiful examples of words being considered as things are provided by the psychotic little boy named Herbert: 'I can't eat "whipped cream", because otherwise, I will be whipped', or, 'I need a first-class ticket, because I am a first-class boy', or else 'I don't want to put on the green coat, I am a big boy, and I don't want to be a frog, I don't want to put on the green coat' (cf. Sterba 1933a and b, my translation).

13. I cannot resist citing a few of the many remarkable linguistic fragments in the case of Herbert, because they illustrate so well that the ways of psychic being are instantiating the dynamics of the living. Herbert says: 'Only living things have a name, things that live and that can be killed'. How remarkable that he grasps the fact that living things have a very peculiar status, that it is those things that have a special relation to names. Herbert says something similar in an even more explicit way: 'One cannot just have a name, one has to be someone, otherwise one cannot live. Therefore, I refuse to say my name, I shall only pronounce my name when I am someone. I want to be alive and grown-up. All adults have a name and are something. I am not the Herbert. Mama just says this; that is only my name, I know, I am really the wagon-manufacturer' (Sterba 1933a: 17, my translation; italics in the original).

\section{References}

Atmanspacher, Harold (1996). Exophysics, endophysics, and beyond. In Revue de la pensée d'aujourd'hui 24 (11), 347-354. [In Japanese.]

Buchler, Justus (ed.) (1955). Philosophical Papers of Peirce. New York: Dover Publications.

Cohen, Aviva (1998). Franz Brentano. L'inspirateur philosophique de Freud. In Aux sources de la psychanalyse. Les premiers écrits de Freud (1877-1900), F. Geerardyn and G. van de Vijver (eds.), 111-122. Paris: L'Harmattan.

Dalto, Sylvana (1998). La genèse du sujet dans la perspective du matérialisme scientifique freudien. In Aux sources de la psychanalyse. Les premiers écrits de Freud (1877-1900), F. Geerardyn and G. Van de Vijver (eds.), 263-273. Paris: L'Harmattan.

Depew, David and Weber, Bruce (1995). Darwinism Evolving: Systems Dynamics and the Genealogy of Natural Selection. Cambridge, MA: MIT Press.

Diamond, Jared (1997). What separates man from the animals? Four inches and eleven minutes. Times Higher Education, July 25.

Evans, Dylan (1996). An Introductory Dictionary of Lacanian Psychoanalysis. London: Routledge.

Freud, S. (1915c). Instincts and their vicissitudes. In The Standard Edition of the Complete Psychological Works of Sigmund Freud, J. Strachey (ed.), vol. 14, 109-159. London: Hogarth Press.

-(1915e). The unconscious. In The Standard Edition of the Complete Psychological Works of Sigmund Freud, J. Strachey (ed.), vol. 14, 161-215. London: Hogarth Press.

-(1950c [1895]). Project for a scientific psychology. In The Standard Edition of the Complete Psychological Works of Sigmund Freud, J. Strachey (ed.), vol. 1, 295-343. London: Hogarth Press.

Griffiths, Paul (1994). Developmental systems and evolutionary explanation. Journal of Philosophy 91 (6), 277-304.

Grunberger, Bela and Chasseguet-Smirgel, Janine (eds.) (1978). L'identification. L'autre, c'est moi. Paris: Tchou. 
Guir, Jean (1998). Lecture on 'Psychosomatics'. Oostende, February 25.

Hoffmeyer, Jesper (1996). Signs of Meaning in the Universe, trans. by Barbara J. Haveland. Bloomington: Indiana University Press.

Kampis, George (1991). Self-modifying Systems in Biology and Cognitive Science. Oxford: Pergamon Press.

Kauffman, Stuart A. (1993). Origins of Order: Self-Organization and Selection in Evolution. New York and Oxford: Oxford University Press.

Lacan, Jacques (1961-1962). Le Séminaire. Book 9, L'identification. Publication hors commerce de l'Association freudienne internationale.

-(1966). Écrits. Paris: Editions du Seuil. [See, in particular, Propos sur la causalité psychique, 151-193.]

-(1993 [1955-1956]). The Seminar. Book 3, The Psychoses, trans. by Russell Grigg. London: Routledge.

-(1977 [1964]). The Seminar. Book 11, The Four Fundamental Concepts of Psychoanalysis, trans. by A. Sheridan. London: Hogarth Press.

Matsuno, Koichiro (ed.) (1996). Revue de la pensée d'aujourd'hui. Special issue on Internalism/Externalism. [In Japanese.]

Matsuno, Koichiro and Salthe, Stanley N. (1995). Global idealism/local materialism. Biology and Philosophy 10 (3), 309-337.

Maturana, Humberto R. (1988). Reality: The search for objectivity or the quest for a compelling argument. Irish Journal of Psychology 9 (1), 33.

Maturana, Humberto R. and Varela, Francisco J. (1980). Autopoiesis and Cognition: The Realization of the Living. Dordrecht: Reidel.

-(1987). The Tree of Knowledge: The Biological Roots of Human Understanding. Boston: Shambhala.

Pattee, Howard (1995). Evolving self-reference: Matter, symbols, and semantic closure. CC-AI 12 (1/2), 9-27.

Petitot, Jean (1985). Morphogenése du Sens I. Pour un schématisme de la structure. Paris: Presses Universitaires de France.

-(1990). Le physique, le morphologique, le symbolique. Remarques sur la vision. Revue de Synthèse 4 (1/2), 139-183.

Reyniers, Françoise and Van de Vijver, Gertrudis (1998). The problem of the cause as the cause of the problem. Psychoanalytische Perspektieven 33, 69-91. [Special issue on Adolf Grünbaum.]

Rosen, Robert (1985). Anticipatory Systems. Oxford: Pergamon Press.

- (1991). Life Itself. New York: Columbia University Press.

Salthe, Stanley N. (1985). Evolving Hierarchical Systems. New York: Columbia University Press.

-(1993). Development and Evolution: Complexity and Change in Biology. Cambridge, MA: MIT Press.

Sheets-Johnstone, Maxine (1996). Consciousness. Paper presented at the International Workshop on Origins of Cognition, San Sebastian, 13-14 December.

Sterba, Edita (1933a). Ein Abnormes Kind. Aus Seiner Krankengeschichte und Behandlung 1. Zeitschrift für Psychoanalytische Pädagogik 7 (1), 5-38.

-(1933a). Ein Abnormes Kind. Aus Seiner Krankengeschichte und Behandlung 2. Zeitschrift für Psychoanalytische Pädagogik 7 (2), 45-82.

Van de Vijver, Gertrudis (1996). Internalism versus externalism: A matter of choice? Contemporary Philosophy 24 (11), 93-101.

-(1997). Review of Signs of Meaning in the Universe, J. Hoffmeyer, 1996. Cybernetics and Human Knowing 4 (4), 65-68. 
- (1998). Sur la structure psychique. Une lecture à partir de l'Esquisse de Freud. In Aux sources de la psychanalyse. Les premiers Ėcrits de Freud (1877-1990), F. Geerardyn and G. van de Vijver (eds.), 225-242. Paris: L'Harmattan.

Van de Vijver, Gertrudis; Salthe, Stanley; and Delpos, M. (eds.) (1998). Evolutionary Systems: Biological and Epistemological Perspectives on Self-organization and Selection. Dordrecht: Kluwer Academic Publishers.

Varela, Francisco (1979). Principles of Biological Autonomy. New York: North Holland.

Gertrudis Van de Vijver (b. 1962) is Senior Research Associate in the Department of Philosophy at the University of Ghent in Belgium 〈gertrudis.vandevijver@rug.ac.bc〉. Her principal research interests include philosphy of science, evolution, self-organization, and structure. Her major publications include 'The relation between causality and explanation in emergentist naturalistic theories of cognition' (1995), 'Aux sources de la psychoanalyse' (ed. with F. Geerardyn, 1998), and Evolutionary Systems: Biological and Epistemological Perspectives on Self-organization and Selection (ed. with Stanley Salthe and M. Delpos, 1998). 